\title{
Conventional Pap Smear Cytology in a Tertiary Care Center
}

\author{
Tika Kumari Gurung, ' Shree Prasad Adhikari, ${ }^{2}$ Ayushma Adhikari, ${ }^{1}$ Reecha Shrestha, ${ }^{1}$ Chum Maya Pun ${ }^{3}$ \\ 'Department of Obstetrics and Gynecology, Gandaki Medical College and Teaching Hospital, Pokhara, Nepal, Department of \\ Obstetrics and Gynecology, ${ }^{2}$ Paropakar Matri Shishu Hospital, Thapathali, Kathmandu, Nepal, ${ }^{3}$ Department of Obstetrics and \\ Gynecology, Pokhara Academy of Health Science, Pokhara, Nepal.
}

\section{ABSTRACT \\ Introduction}

Cervical cancer is the fourth most common cancer in women with high mortality. Since it is a preventable cancer, screening for cervical cancer with Papanicolaou test (Pap Test) is considered as the stepping stone in its cure by detecting at its premalignant state. The two methods of acquiring the sample for cytology are Conventional method and liquid based cytology.

\section{Methods}

The Pap test results of the patients who visited the outpatient clinic of the Gynecologic Department of Gandaki Medical College and Teaching Hospital from January 2012 to December 2017 were reviewed and analyzed from the medical records. The findings of Pap test results were tabulated and categorized as per Bethesda system of classification (2001).

\section{Results}

A total of 2004 Pap tests were taken. All of the patients in the study were married with mean age of $39.7 \pm 10.3$ years. A total of $1291(64.42 \%)$ Pap tests were normal or negative for intraepithelial lesion whereas $578(28.84 \%$ ) were inflammatory smears while $37(1.85 \%)$ were inadequate for evaluation. There was a presence of low grade intraepithelial lesion in $4(0.2 \%)$ and high grade intraepithelial lesion in 15(0.75\%). Atypical squamous cell of undetermined significance (ASCUS) was noted in $11(0.55 \%)$ and frank malignancy was noted in $1(0.05 \%)$ of total Pap test samples.

\section{Conclusions}

In a developing country like Nepal, Pap test is still the preferred cervical cancer screening tool. All women should undergo the screening test for cervical cancer with any feasible available test.

Keywords: Bethesda system; cervical cancer; HPV; Pap Test.

Correspondance: Dr. Tika Kumari Gurung, Department of Obstetrics and Gynecology, Gandaki Medical College and Teaching Hospital, Pokhara, Nepal. Email: tikanirvana18@gmail.com. Phone: +977-9808704566. 


\section{INTRODUCTION}

Cervical cancer is the most common cancer in women in low resource countries, ${ }^{1}$ accounting for $87 \%$ deaths in those regions. ${ }^{2}$ In Nepal, cervical cancer is the most frequent cancer among women with an estimate of approximately $2.0 \%$ of women in the general population. ${ }^{3}$ Approximately 99.7\%, is caused by human papillomavirus $(\mathrm{HPV}){ }^{4}$ particularly $\mathrm{HPV}-16$ and 18 serotypes. ${ }^{4,5}$

The World Health Organization (WHO) advocates a comprehensive approach to cervical cancer prevention and control. ${ }^{6}$ And stated screening of all women aged 35-50 years at least once in a lifetime. ${ }^{7}$ Cervical cancer screening aims to identify high-grade, precancerous cervical lesions early. ${ }^{8}$ with a focus on clinical trials and cohort studies that evaluated screening with high-risk human papillomavirus (hrHPV Papanicolaou smear screening (cervical cytology) is considered a good method for detecting early cervical cancer in Nepal despite queries regarding its feasibility. ${ }^{9}$

This study aims to analyze the different outcomes of Pap tests and compare the outcomes of the study with other similar studies.

\section{METHODS}

This is a retrospective descriptive study. The results of all pap tests done from the year 2012 to 2017 were retrieved from the records of the department of pathology. All the pap tests samples were taken with conventional method at the outpatient department of obstetrics and gynecology of Gandaki Medical College Teaching Hospital. In a conventional method of Pap test, the sample from the cervix was first taken with a spatula by rotating in the ectocervix and making a smear in a glass slide which was then immersed in 95\% ethanol. Similarly a cytobrush was then inserted in the cervical os, a smear specimen is made in another glass slide and immersed in 95\% ethanol. These two slides immersed in a fixative ethanol were sent to the laboratory for analysis. The laboratory results were reported according to Bethesda System for reporting cervical cytology (2001). Since this study included samples from 2012, we used the 2001 Bethesda system for reporting the Pap test results.

Cytology results were reported according to the Bethesda III Classification System (2001) as follows:

\section{a. Specimen adequacy}

- Satisfactory

- Unsatisfactory

\section{b. Interpretation/Results}

- Negative for intraepithelial lesion/ malignancy

- Epithelial cell abnormalities

i. Squamous cell abnormalities

- Atypical squamous cells (ASCs)

- ASC of undetermined significance (ASCUS)

- ASC that cannot rule out highgrade lesion (ASCH)

- Lowgrade squamous intraepithelial lesion (LSIL)

- Highgrade squamous intraepithelial lesion (HSIL)

- Squamous cell carcinoma (SCC)

ii. Atypical Glandular cell abnormalities

- Atypical glandular cells, specify site of origin, if possible

- Atypical glandular cells, favor neoplasia

- Adenocarcinoma in situ

- Adenocarcinoma

\section{c. Other cancers (List not comprehensive)}

Endometrial cells in a woman $\geq 40$ years of age 


\section{RESULTS}

A total of 2004 patients were screened with Pap test with conventional methods during the six year period from January 2012 to December 2017 at the outpatient of Obstetrics and gynecology department.

The age ranged from 21 to more than 70 with a mean age of mean age of 39.5 years \pm 10.3 years. The majority of women included in this study were in age group 36-40 years with mean age of 39.5 years \pm 10.3 years.

\begin{tabular}{|l|l|}
\hline \multicolumn{2}{|c|}{$\begin{array}{c}\text { Table 1. Table showing distribution of patients } \\
\text { according to different age group. }\end{array}$} \\
\hline \multicolumn{1}{|c|}{ Age Group } & \multicolumn{1}{|c|}{ Number of patients (\%) } \\
\hline $21-25$ & $101,5.04 \%$ \\
\hline $26-30$ & $316,15.77 \%$ \\
\hline $31-35$ & $363,18.11 \%$ \\
\hline $36-40$ & $395,19.71 \%$ \\
\hline $41-45$ & $312,15.57 \%$ \\
\hline $46-50$ & $223,11.13 \%$ \\
\hline $51-55$ & $141,7.04 \%$ \\
\hline $56-60$ & $83,4.14 \%$ \\
\hline $61-65$ & $39,1.95 \%$ \\
\hline $66-70$ & $22,1.10 \%$ \\
\hline$>70$ & $9,0.45 \%$ \\
\hline total & 2004 \\
\hline
\end{tabular}

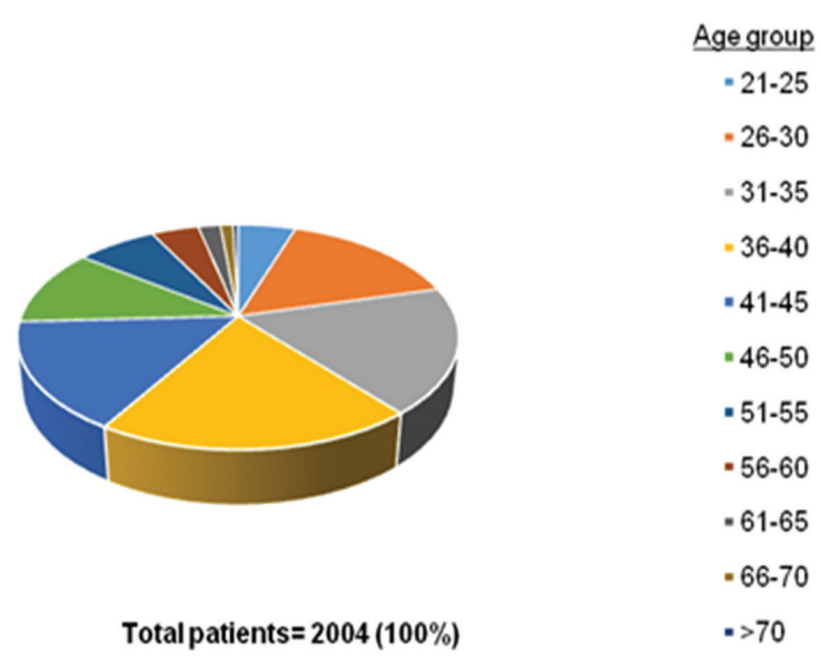

Table 2. Table showing Pap Smear Results according to Bethesda III (2001) classification

\begin{tabular}{|l|c|c|}
\hline Cytodiagosis & No. of patients(n) & Frequency(\%) \\
\hline NILM & 1291 & 64.42 \\
\hline Inflammatory & 578 & 28.84 \\
\hline ASCUS & 11 & 0.55 \\
\hline
\end{tabular}

SIL

\begin{tabular}{|c|c|c|}
\hline$\bullet \quad$ LSIL & 4 & 0.20 \\
\hline$\bullet H S I L$ & 15 & 0.75 \\
\hline
\end{tabular}

Carcinoma

\begin{tabular}{|r|c|c|}
\hline$\bullet \quad$ SCC & 1 & 0.05 \\
\hline ADC & 0 & 0.00 \\
\hline Inadequate & 37 & 1.85 \\
\hline Unsatisfactory & 12 & 0.60 \\
\hline Reactive & 25 & 1.25 \\
\hline Atrophy & 30 & 1.50 \\
\hline Total patients & 2004 & 100 \\
\hline
\end{tabular}

Of the 2004 Pap smears, 64.42\% (1291) were found to be normal, while $28.84 \%$ (578) were evaluated as inflammatory smear, $0.55 \%$ were ASCUS, $0.75 \%$ as HSIL and $0.20 \%$ as LSIL. Frank malignancy was noted in $0.05 \%$ (1) and $1.50 \%$ (30) as atrophy, $1.25 \%$ (25) showed reactive cellular changes and $1.2 \%$ (11) as atypical squamous cells.

This table shows cytology findings of Pap tests in various age groups. ASCUS was noted between 26 to 60 years of age with most cases between age 51-55 years. HSIL from 41 to 70 years of age with most cases also between 52-55 years of age. Two cases of HSIL were noted in women more than 65 years of age. 
Table 3. Table showing age-wise distribution of neoplastic and non-neoplastic lesions.

\begin{tabular}{|l|c|c|c|c|c|c|c|c|c|}
\hline $\begin{array}{c}\text { Age Group } \\
\text { (year) }\end{array}$ & NIL & Inflammatory & LSIL & HSIL & ASCUS & Malignancy & reactive & inadequate & atrophy \\
\hline $21-25$ & 72 & 28 & 0 & 0 & 0 & 0 & 1 & 0 & 0 \\
\hline $26-30$ & 219 & 86 & 1 & 0 & 2 & 0 & 3 & 3 & 0 \\
\hline $31-35$ & 237 & 114 & 1 & 0 & 1 & 0 & 1 & 7 & 0 \\
\hline $36-40$ & 262 & 116 & 1 & 0 & 1 & 0 & 7 & 5 & 0 \\
\hline $41-45$ & 195 & 102 & 0 & 3 & 1 & 0 & 3 & 6 & 0 \\
\hline $46-50$ & 152 & 53 & 0 & 2 & 2 & 0 & 3 & 7 & 2 \\
\hline $51-55$ & 75 & 41 & 1 & 4 & 3 & 0 & 4 & 4 & 9 \\
\hline $56-60$ & 41 & 22 & 0 & 2 & 1 & 0 & 2 & 3 & 12 \\
\hline $61-65$ & 20 & 10 & 0 & 2 & 0 & 0 & 1 & 2 & 4 \\
\hline $66-70$ & 11 & 6 & 0 & 2 & 0 & 0 & 0 & 0 & 3 \\
\hline$>70$ & 7 & 0 & 0 & 0 & 0 & 1 & 0 & 0 & 0 \\
\hline Total & 1291 & 578 & 4 & 15 & 11 & 1 & 25 & 37 & 30 \\
\hline
\end{tabular}

The malignancy (SCC) rate in our study was $0.05 \%$, HSIL $0.75 \%$, LSIL $0.20 \%$ and ASCUS $0.55 \%$. countries. ${ }^{15}$

According to National Registry Program by B.P.

Table 4. Table showing comparison of distribution of neoplastic lesions with previous studies

\begin{tabular}{|l|c|c|c|c|c|}
\hline \multicolumn{1}{|c|}{ Studies } & ASCUS(\%) & LSIL(\%) & HSIL(\%) & Malignancy (\%) & Total patients \\
\hline Current Study & 0.55 & 0.20 & 0.75 & 0.05 & 2004 \\
\hline Thapa et. al. $^{10}(2018)$ & 1.18 & 1.56 & 0.52 & 0.42 & 2113 \\
\hline Verma et al., $^{11}(2016)$ & 1 & 5.5 & 2.5 & 0 & 200 \\
\hline Kalyani et al., $^{12}(2016)$ & 1.46 & 0.24 & 0.41 & 0.41 & 1234 \\
\hline${\text { Malpani et. al. }{ }^{13}(2016)}^{\text {Patel et al. }}{ }^{14}(2011)$ & 0.42 & 0.57 & 0.54 & 0.51 & 7127 \\
\hline
\end{tabular}

\section{DISCUSSION}

Cervical cancer is a preventable and curable when diagnosed early. This is also one of the most screened cancer worldwide. In the last five decades, population based cervical cytology programs with Papanicolaou testing every 3-4years have significantly reduced the incidence and mortality associated with cervical cancer by upto $80 \%$ in developed
Koirala Memorial Cancer Hospital, Bharatpur cervical cancer was noted most frequently in women aged 35-64 years old and is the second most common cancer after lung cancer in Nepal. Albeit frank malignancy was noted only in woman of more than 70 yrs old in our study. According to Human Papillomavirus and Related Cancers, Fact Sheet 2017 every year 2332 women are diagnosed with cervical cancer and 1367 die from the disease. It is 
the most frequent cancer among women in Nepal between 15 and 44 years of age with peak incidence between 45 to 65 years of age. ${ }^{3}$ Normally a Pap test is advised for women age 21 years and above and not beyond 65 years of age. But with any suspicious cervix, a pap test should be offered at the out-patient which led to the finding of Squamous Cell Carcinoma (SCC) in a pap done in a woman $>70$ years of age in our study. In the same way HSIL was noted in two women in 66-70 years of age. These findings signify the importance of an opportunistic screening in a woman who has never had a single Pap test in her lifetime. A study on opportunistic screening for cervical cancer done by Kulkarni et. al. showed a malignant lesion in $4.65 \%$ of the sample and premalignant lesion in $95.35 \% .{ }^{16} \mathrm{a}$ total of 350 cervical smears were studied. The age of patients ranged from 19 years to 80 years with mean age being 37.5 years. Out of 350 cases, the diagnosis of neoplasia was given in 43 cases and 258 cases were diagnosed as inflammatory smears. Forty-cases were normal and 9 cases were inadequate to evaluate. Forty-three patients who were found to have neoplastic lesions on cytology were referred for further investigations like colposcopy and biopsy to confirm the diagnosis and avail proper treatment. Limitation of the present study was small sample size as all female patients aged between 20 and 60 years visiting hospital were not included in the screening, other screening tests like VIA (visual inspection with acetic acid test In our study all women were married and the mean age while undergoing Pap test was $39.7 \pm 10.3$ years. In the present study, abnormal cytology such as HSIL, LSIL and ASCUS were noted in the age group of 41-55. The U.S. Preventive Services Task Force (USPSTF) on 2018 published the recommendation on the cervical cancer screening in an average risk women. And the screening recommendation is in women 21-29 years cervical cytology alone every 3 years, in women 30-65 years , cervical cytology alone every 3 years or high risk HPV testing (hrHPV) alone every 5 years or co-testing (hrHPV and cytology) alone every 5 years. For women aged $>65$ years with adequate previous screening, no screening is recommended. ${ }^{17}$

NILM was reported in 1291 women (64.42\%) while inflammatory smear was noted in 578 women $(28.84 \%)$ in this study. Furthermore, this study observed ASCUS in 11 women $(0.55 \%)$, LSIL in 4 women $(0.20 \%)$, HSIL in 15 women $(0.75 \%)$ and SCC in 1 woman $(0.05 \%)$. In the study by Maleki et. al. $89.3 \%$ of 5000 subjects had inflammatory changes and cervical dysplasia was observed in 173 cases $(4.04 \%)$. Of these cervical dysplastic changes, 81 cases (47.2\%) were ASCUS, 40 cases (23\%) were ASCH, 43 cases (24.7\%) were LSIL, 6 cases $(3.46 \%)$ were HSIL and 3 cases $(1.73 \%)$ were AGUS changes. ${ }^{18}$

The studies done by Thapa et. al. (2018), Verma et. al. (2017) and Malpani et. al. (2016), showed LSIL as the most common lesion while HSIL was the most common lesion in this study. Malignancy was noted in $0.05 \%$ of the patients in this study which was the least common neoplastic finding and this was comparable with the study done by Thapa et. al. and Verma et. al. ASCUS was the most frequently occuring lesion in the studies by Kalyani et. al. (2016) and Patel et. al. (2011).

\section{CONCLUSIONS}

Cervical cancer is a preventable and curable cancer when diagnosed on time. An immense effort from various sectors are needed to curb the morbidity and mortality. In a developing country like Nepal, as compared to women 10 years back, women these days are aware of cervical cancer but still only few women 
seek consult for the screening purpose only. The two main strategies emphasized by WHO in combating this problem is through education and screening. Pap test being the

\section{REFERENCES}

1. Arbyn M, Weiderpass E, Bruni L, de Sanjosé S, Saraiya M, Ferlay J, et al. Estimates of incidence and mortality of cervical cancer in 2018: a worldwide analysis. Lancet Glob Health. 2019 Dec 4;8(2):e191-203.

2. Ferlay J, Soerjomataram I, Dikshit R, Eser S, Mathers C, Rebelo M, et al. Cancer incidence and mortality worldwide: sources, methods and major patterns in GLOBOCAN 2012. International journal of cancer. 2015;136(5):E359-E386.

3. Nepal: Human Papillomavirus and Related Cancers, Fact Sheet 2019. Fact Sheet. 2018;2.

4. Clifford GM, Smith JS, Plummer M, Munoz N, Franceschi S. Human papillomavirus types in invasive cervical cancer worldwide: a meta-analysis. British journal of cancer. 2003;88(1):63-73.

5. Chan CK, Aimagambetova G, Ukybassova T, Kongrtay K, Azizan A. Human Papillomavirus Infection and Cervical Cancer: Epidemiology, Screening, and Vaccination-Review of Current Perspectives [Internet]. Vol. 2019, Journal of Oncology. Hindawi; 2019 [cited 2020 Aug 10]. p. e3257939. Available from: https://www.hindawi.com/journals/ jo/2019/3257939/

6. 9789241505147_eng.pdf [Internet]. [cited 2020 Aug 10]. Available from: https://apps.who.int/iris/bitstream/ safest, cheapest and easy method of screening, women are encouraged to undergo this test or any screening test available in their health facility. handle/10665/78128/9789241505147_eng. pdf;jsessionid $=\quad$ EBD391DC22CDB0507 EF7506A88C7B26D? sequence=3

7. Sankaranarayanan R, Budukh AM, Rajkumar R. Effective screening programmes for cervical cancer in lowand middle-income developing countries. Bulletin of the World Health Organization. 2001;79:954-962.

8. Curry SJ, Krist AH, Owens DK, Barry MJ, Caughey AB, Davidson KW, et al. Screening for Cervical Cancer: US Preventive Services Task Force Recommendation Statement. JAMA. 2018 Aug 21;320(7):674-86.

9. Gakidou E, Nordhagen S, Obermeyer Z. Coverage of Cervical Cancer Screening in 57 Countries: Low Average Levels and Large Inequalities. PLOS Medicine. 2008 Jun 17;5(6):e132.

10. Thapa N, Shrestha G, Maharjan M, Lindell D, Maskey N, Shah R, et al. Burden of cervical neoplasia in mid-western rural Nepal: a population-based study. J Gynecol Oncol [Internet]. 2018 Sep [cited 2020 Aug 25];29(5). Available from: https:// www.ncbi.nlm.nih.gov/pmc/articles/ PMC6078891/

11. Verma A, Verma S, Vashist S, Attri S, Singhal A. A study on cervical cancer screening in symptomatic women using Pap smear in a tertiary care hospital in rural area of Himachal Pradesh, India. Middle East Fertility Society Journal. 2017 Mar 1;22(1):39-42. 
12. R K, Sharief N, Shariff S. A Study of Pap Smear in a Tertiary Hospital in South India. Journal of Cancer Biology \& Research [Internet]. [cited 2020 Sep 19]; Available from: https://www.jscimedcentral.com/ CancerBiology/cancerbiology-4-1084.php

13. Malpani G, Agrawal P, Varma AV, Khandelwal N, Tignath G. Cervical Pap smear study and detection of abnormal epithelial lesions and determination of its accuracy by cytohistological correlation in patients of tertiary care teaching hospital in central India. International Journal of Reproduction, Contraception, Obstetrics and Gynecology. 2017 Feb 23;5(7):2312-6.

14. Pandya D amrish. Cervical Pap smear study and its utility in cancer screening, to specify the strategy for cervical cancer control in our set up. National journal of community medicine. 2011 Jan 1;2.

15. Nayir T, Okyay RA, Nazlican E, Yesilyurt H, Akbaba M, Ilhan B, et al. Cervical Cancer Screening in an Early Diagnosis and Screening Center in Mersin, Turkey. Asian Pacific Journal of Cancer Prevention. 2015 Nov 4;16(16):6909-12.

16. Kulkarni PR, Rani H, Vimalambike MG, Ravishankar S. Opportunistic Screening for Cervical Cancer in a Tertiary Hospital in Karnataka, India. Asian Pacific Journal of Cancer Prevention. 2013 Sep 30;14(9):5101-5.

17. Cervical Cancer Screening (Update) [Internet]. [cited 2020 Aug 14]. Available from: https://www.acog.org/en/Clinical/ Clinical Guidance/Practice Advisory/ Articles/2018/08/Cervical Cancer Screening Update

18. Maleki A, Ahmadnia E, Avazeh A, Mazloomzadeh S, Molaei B, Jalilvand A. Prevalence of Abnormal Papanicolaou Test Results and Related Factors among Women Living in Zanjan, Iran. Asian Pacific Journal of Cancer Prevention. 2015 Nov 4;16(16):6935-9.

Citation: Gurung T, Adhikari S, Adhikari A, Shrestha R, Pun C. Conventional Pap Smear Cytology in a Tertiary Care Center. JCMS Nepal. 2021 ; 17(2); 117-23. 